\title{
Asking Questions: A Sine Qua Non of Facilitation in Decision Support?
}

\author{
Marleen McCardle-Keurentjes $^{1}$ • Etiënne A. J. A. Rouwette $^{1}$
}

Published online: 23 May 2018

(C) The Author(s) 2018

\begin{abstract}
This paper reflects our ongoing interest in discovering essential elements of facilitation in decision support for groups with members having different perspectives on a strategic problem. We investigated questioning behaviour, a critical aspect of microlevel behaviour, of the facilitator in a classroom experiment with five-person groups $(\mathrm{N}=26)$. The supported groups used a facilitated modelling approach, that is, group model building, which is based on system dynamics. In the control condition, one of the participants led the group discussion in the role of chairperson. As expected, we found that the facilitator asked more questions than the chairperson. Subsequently, based on proposed functions of questions by discussion leaders in group decision making, we distinguished three categories of questions; related to (a) rational and social validation, (b) reflection, and (c) information management. Analysis of question type frequencies revealed that facilitators mainly ask questions from the rational and social validation category, and that this question type declines over the course of the discussion process. Questions prompting reflection increased over time. Information management questions were mostly used in the beginning and middle part of the session. In the groups led by a chairperson, a less clear picture emerged. There was a great variety between groups with respect to type of questions and sequence in which the chairperson asked questions. The only consistent result for unsupported meetings is that information management primarily took place at the end of the sessions.
\end{abstract}

$凶 \quad$ Etiënne A. J. A. Rouwette

E.Rouwette@fm.ru.nl

Marleen McCardle-Keurentjes

m.mccardle@fm.ru.nl

1 Institute for Management Research, Radboud University, Elenor Ostrom Building,

Heyendaalseweg 141, P.O. Box 9108, 6500 HK Nijmegen, The Netherlands 
Keywords Decision support · Facilitated modelling - Group facilitation · Group model building · Question asking

\section{Introduction}

Managers experience strategic decision making problems often as "messes" (cf. Ackoff 1979, p. 99). Strategic problems consist of issues relating developments inside and outside the organisation. Change in the problem situation occurs at different times and places (Pettigrew 1992). Each issue independently influences developments in the problem but more than that, the interaction between issues shapes problem behaviour (Ackoff 1979) and gives rise to the perception of messiness. In addition to complexity due to interaction between issues, different and sometimes conflicting perspectives of stakeholders complicate a strategic problem. Organisations confronted with this kind of problem may turn to a range of decision support approaches (Morton et al. 2003). In one particular form of decision support, known as facilitated modelling, two instruments are important: the construction of a model of the problem situation and facilitation of the group decision making process in a participatory way (Franco and Montibeller 2010). These model-driven approaches bring stakeholders together in face-to-face meetings, aimed at exchanging information and perceptions on the problem in a learning process (Eden 1995; Morton et al. 2003). Facilitated modelling approaches emerged at the end of the 1970s from the realisation that complex problems make it necessary to elicit and compare multiple perspectives to handle a problem (Morton et al. 2003). These approaches were therefore designed to help stakeholders to exchange diverse information and perspectives, combine insights, and jointly determine how to manage the messy situation.

Numerous studies, mainly executed in natural settings, have reported positive outcomes supporting the value of facilitated modelling approaches in these settings (see e.g., Phillips 2007; Rouwette et al. 2002; Scott et al. 2016). It is difficult, however, to clearly establish the link between context, process and outcomes of decision support (Schilling et al. 2007). In natural settings, the context in which a facilitated modelling approach is used and how the approach is used in that context, is largely beyond the control of researchers (Finlay 1998; Rouwette et al. 2009). Several authors have called for research that builds understanding of the process of decision support in messy problem situations (see e.g., Brocklesby 2016; Franco and Montibeller 2010; Hämäläinen et al. 2013). Numerous factors influence the outcomes of model-driven decision support. Facilitated modelling includes support both with regard to the content of the problem at hand and the (social) process during group work; building a model in a participatory way boils down to balancing technical and analytical aspects with human and social aspects (Huxham and Cropper 1994; Brocklesby 2016). As pointed out by Eden (1989 in Brocklesby 2016, p. 799), positive outcomes depend more on using decision support "in the meaningful context in which it occurs" rather than on "the veracity or elegance of technical solutions". Depending on the context, for instance the political sensitivity of a problem, comparable processes will lead to different outcomes. For studies in natural settings, it has proven to be difficult to separate the effect of context from process factors (Rosenhead and Mingers 2001; 
Rouwette et al. 2002). More systematic research is needed to identify effective process elements at work in facilitated modelling (Andersen et al. 2007; Midgley et al. 2013; Rouwette et al. 2002; Scott et al. 2016). The present study responds to this need by addressing a process element, that is, asking questions by the facilitator, in a classroom experiment. This research design enabled us to explore facilitation at the microlevel, that is, by analysing observable behaviour shown in the process of decision support. Questioning (i.e., asking questions) is verbal behaviour that can be observed, operationalised in our study as the act "to elicit a verbal response from those to whom the question is addressed" (Kersley 1976 in Hawkins and Power 1999, p. 236). The direct examination of microlevel behaviour allowed us to come to conclusions based on observations of characteristics for which objective measures can be found. This can be seen as complementary to research that —although valuable-hinges on subjective (self) evaluations of decision making support (Rosenhead and Mingers 2001; Rouwette et al. 2002; Scott et al. 2016).

A better understanding of what happens in facilitated modelling is important from a theoretical but also from a practical point of view. As a participatory process always requires resources from organisations that need to be planned and justified, facilitators and their contact persons in organisations must be able to motivate the choice of a decision support approach (Eden and Ackermann 1996). A better understanding of how the process affects outcomes of decision support will enable them to better compare available options and justify their choice. In addition, evidence of which process elements work - or do not work - and why, will be of interest for developers of training programmes for novice facilitators. More insight into the facilitated modelling process can be reflected and stored in scripts (Ackermann et al. 2010; Hovmand et al. 2012): Steps as well as the reason why steps are to be taken in a particular way, can be described more specifically. These insights can support novice facilitators in choosing a design for a session or project. More elaborated and substantiated scripts improve the basis for evaluating facilitated modelling practices. This ultimately benefits both experienced facilitators and novices, by giving them valuable ideas on further improvements in decision support.

In messy problem situations, personal or human elements inherently have a role (Morton et al. 2003). With multiple stakeholders involved in the group process, facilitated modelling is bound to be influenced by human behaviour (Hämäläinen et al. 2013). Human behaviour is not only related to group members participating in the modelling process but also to the facilitator guiding the process. Group facilitation intends to help groups accomplish their task more efficiently and effectively (Kolfschoten et al. 2012). Facilitators support decision-making groups by helping group members to use their information resources optimally and by counteracting potential dysfunctions, such as cognitive inertia, groupthink, and information overload (Franco and Montibeller 2010). Model-based decision support often explicitly takes a process consultation perspective which means that the facilitator aims to establish a helping relationship with the client (Franco and Montibeller 2010; Morton et al. 2003; Schein 1997). An important part of process consultation perspective is that the facilitator engages in genuine exploratory inquiry (Schein 1997). Schein sees each act of the facilitator as an intervention that influences the client's behaviour, thinking and feelings. "(...) Every question [emphasis added] or inquiry is (...) an intervention and must 
be treated as such" (p. 207). This underscores the relevance of examining microlevel behaviour of the facilitator. If the facilitator's behaviour has such a great impact, it seems imperative that facilitators reflect on their actions and the effects they evoke.

As already stated, constructing a model and facilitation of the process in a participatory way are the two main instruments of model-based decision support. When using facilitated modelling, the facilitator guides the group through the discussion process. We selected 'asking questions' as our focus since asking questions is a direct way to guide a discussion process (Edmondson et al. 2003; Meyer et al. 2016; Vennix 1996). The facilitator's role is to help group members to articulate their views and explore differences and commonalities, while jointly modelling the problem. This requires asking questions to participants (Franco and Montibeller 2010).

Some studies have investigated questioning by discussion leaders. For instance, Korsgaard et al. (1995) showed that questioning by leaders matters in strategic decision making groups. They found that a strong consideration of group members' input (i.e., by rephrasing statements, asking questions for clarification, and taking notes) affect evaluations of group members about fairness of the process positively as well as commitment to the decision. Meyer et al. (2016) showed that leaders encouraging participation asked more questions than leaders having a directive style of leadership. ${ }^{1}$ Asking questions mediated the relationship between participative leadership and decision quality. Also Larson et al. (1998) showed that asking questions is related to leadership behaviour; in their study, leaders compared to group members asked more questions. However, to the best of our knowledge, with the exception of McCardleKeurentjes (2015), questioning has not been studied by systematically comparing groups using decision support to unsupported groups.

A logical first step is to identify the number of questions asked as an indicator of the guidance provided in the process, and see whether the frequency differs between supported and unsupported groups. Also, different types of questions can be identified and compared on how many questions are asked per type. However, this first step of comparing numbers of questions is not sufficient if we want to establish relationships between decision support and the resulting process. Frequency data can be appropriate, but according to Hackman and Morris (1975), it is uncertain whether specific communication acts such as the number of questions will affect outcomes. Hackman and Morris give the example of a chess game, for which we would not expect that the difference between winning and losing a game can be meaningfully explained on the basis of for instance the total number of moves of pawns. Instead, looking at clusters of moves or sequences will be more meaningful. Before we can do that, however, we need to know which sequences are relevant. Hackman and Morris therefore advise to start from a conceptual framework that clarifies the essential factors that shape outcomes, or in other words, identify links between context, process and outcomes (see also Eden 1995; Rouwette et al. 2009). Our study therefore focuses on one particular aspect of the process of decision support, that is, questions posed by facilitators in terms of total

\footnotetext{
1 Participative leaders were instructed to stimulate discussion, ensure participation of all, provide ideas about how to proceed in the discussion and to avoid forcing one's own opinion on the group. Directive leaders were instructed to be the first to suggest the optimal solution, to determine both the discussion procedure and the optimal solution, and to interrupt unsuitable contributions.
} 
number of questions of different types (frequency) as well as developments of types over time (sequence).

In this study, the facilitator of groups using decision support, is a person external to the decision making group. This person directly communicates with group members to elicit and integrate information (into a model), and pays attention to dynamics in the group at the same time (Nelson and McFadzean 1998; Richardson and Andersen 1995). The person guiding the groups in the control condition (i.e., the unsupported groups) is a member of the decision making group. He or she contributes to the discussion in a management position while also guiding the group discussion in the role of chair. The term 'discussion leader' covers both of these roles: the facilitator in the supported groups as well as the chairperson in the unsupported groups.

In the following, we first introduce the facilitated modelling approach used in this study: group model building. Next, we address questioning in discussion processes and identify functions of questions asked by discussion leaders, resulting in a typology of questions. We subsequently present the classroom experiment in which we examined whether facilitators ask more questions in guiding a decision making discussion than chairpersons. Further, based on the typology of questions, we analysed the type of questions asked by discussion leaders over time in both conditions. In the last section of this paper, we reflect on the results and propose future research directions.

\section{Group Model Building}

The intervention studied in this paper is one particular type of facilitated modelling with which the authors have first-hand experience: group model building. Group model building is a facilitated modelling approach rooted in system dynamics and particularly suited to support a learning process in which a shared and more comprehensive understanding of the problem situation is created (Vennix 1996). In order to decide on how to manage such a problem, a comprehensive view on the problem situation is needed. The interaction between the interrelated issues in the problem situation (the mess) should be considered (Ackoff 1979). Group model building takes a holistic view by helping the problem owners to identify relations between problem elements. Holism refers to gaining understanding of "the whole problematic phenomenon, instead of understanding parts or aspects of it" (Bleijenbergh et al. 2011, p. 150).

When supported with group model building, the facilitator helps the group to develop a system dynamics model of a strategic problem. In the qualitative mode, the participants construct a causal loop diagram, showing connections between concepts by (chains of) causal relations. Constructing a model requires elicitation of group members' ideas and opinions, and identification of communalities as well as differences in participants' contributions. The first step in the group interaction is a modified version of Nominal Group Technique (NGT; Van de Ven and Delbecq 1974), which asks participants to note down variables in the problem situation individually. After a few minutes these variables are gathered in a round-ribbon fashion and noted for all to see. Guided by the facilitator, the group will then elaborate on these contributions until integration of ideas emerges and the point is reached that the model captures the group members' shared view on the problem. A computer program and a screen, 
or pencils, flip charts and/or whiteboard, are tools that are used to sketch the model as it develops (Rouwette 2003). The facilitator takes care to include only those elements in the model on which all participants agree. This is important, because group members will differ in the concepts and relationships each of them uses to represent the problem situation. The resulting model on which all participants agree serves as the basis for discussion about potential policies. The discussion process thus consists of both divergent activities to elicit information and ideas, and convergent activities to reach a shared view on the content of the discussion. Encouraging participation is a major aspect of facilitation as contributions from all group members are essential for reaching a shared view on the problem and commitment to policies (Franco and Montibeller 2010; Vennix 1996). The development of a causal loop diagram generally requires three meetings of about three hours each (Rouwette et al. 2016) but fewer and longer meetings are not uncommon (e.g., de Gooyert et al. 2016 use one workshop of four hours). In the quantitative mode, the group develops a stock and flow model that shows the connections between accumulations and in- and out-flows. Such a formal model is suitable for the simulation of various scenarios of action and requires more time from the group (Rouwette et al. 2002).

Building a system dynamics model is useful, because such a model reveals the causal relations between problem elements, and allows to examine alternative policies based on feedback between the problem elements (Sterman 2000). Moreover, constructing a system dynamics model with a group of stakeholder is useful as modelling in a participatory way allows stakeholders to learn about perspectives of others and to gain new insights on the problem. It is hoped that the process helps the group members to better understand how decisions affect the environment relevant to their problem, and how this in turn will influence decisions again (Andersen et al. 2007; Forrester 1968; Vennix 1996).

Group model building is supposed to accomplish the following. First of all, the goal is "to create a climate in which team learning can take place to enhance understanding of the problem" (Vennix 1996, p. 6). Second, the aim is to foster consensus between the group members about how to tackle their problem and third, to contribute to development of commitment to the decision. There is no hierarchical ordering of the goals. However, we believe the realisation of a climate for open discussion is a prerequisite for gaining more understanding on the problem. Understanding of the problem is needed before consensus and commitment to the decision become relevant and meaningful (Black and Andersen 2012). Communication, in turn, is necessary to share information between participants and integrate their views in a shared model. Thus, communication is at the heart of group model building (Rouwette and Smeets 2016). In the group discussion, the facilitator guides the group communication and it's here, in the discussion process that the open climate necessary to build understanding is created.

\section{Asking Questions in Discussion Processes}

Already in the 1950s, Bales started to observe the discussion process of small problem solving groups in the laboratory (Bales 1951, 2002). Asking questions is one of the four main categories in the coding scheme he developed to assess verbal behaviour of 
groups: Interaction Process Analysis (IPA). Discussions serve task performance and social-emotional purposes and IPA uses four main categories reflecting these purposes (Bales 2002; Beck and Keyton 2009). Questions (e.g., asking for opinions or suggestions) are seen as task-related contributions; instrumental and information oriented. Other task-related contributions are attempted answers (also called 'initial problem solving attempts') such as giving an opinion or suggestion. Socio-emotional contributions are classified as positive reactions (e.g., agreements or statements showing solidarity) or negative reactions (e.g., statements showing disagreement or tension). Bales (2002) characterised the general nature of the process as a feedback system of communication and control. Problem solving attempts may be followed by positive or negative reactions; forming sequences through a repetitive cycle. Questions may start the cycle or be asked at a later point. In several studies of small discussion groups questioning accounted for only a small part of the discussion: $7 \%$ for asking questions versus $56 \%$ for attempted answers, $26 \%$ for positive reactions and $11 \%$ for negative reactions (Bales 2002). To explain the low number of questions asked, Bales pointed to the nature of questioning. By asking a question, the sender provides room to another person for contributing to the discussion. This means that the sender gives up his or her speaking turn and therefore the opportunity to strengthen one's own position. According to Bales only those having a high status (or accepting a low status), can allow themselves to ask a question. He also supposed that questions were asked more often after a period of tension in the group resulting from, for instance, disagreements, and repairing premature problem solving attempts. A question will probably not evoke an affective or negative reaction, and can help the group to focus and proceed in a neutral way. "Questions provide 'a neutral way out', a "patch-up procedure' of last recourse when negative reactions are anticipated" (Bales 2002, p. 245 , italics in original). Gunnarsson (2006, p. 290) explained that a question is a way to express one's views towards an issue more weakly than a statement. A question that starts, for instance, with "Would it be (...)?" includes a lower commitment to one's position in comparison to an expression of one's position in a statement.

Bales' findings, especially on the small number of questions asked in groups relative to the category of problem solving attempts, are interesting as his research focused on processes in initially leaderless groups, and points to areas in which decision support may be particularly useful. He found that groups often fail to use their information effectively and suggested that "better orientation to the problem and more information about the facts at the beginning of meetings, if not all the way through, might improve problem solutions with regard to the task" (Bales 2002, p. 239). In that case, more questioning would be beneficial as a means to elicit more of the information available in the group. In our view, questioning contributes to the procedural rationality of the decision making process. Procedural rationality refers to the degree to which decision relevant information is collected and analysed (Dean and Sharfman 1996) and "the effectiveness, in light of human cognitive powers and limitations" (Simon 1990, p. 9). Dean and Sharfman (1996) found that a higher degree of procedural rationality resulted in more effective decision making. We assume that asking questions makes it more likely that decision relevant information is collected. Questioning may be powerful to improve the exchange and following use of information, which is an important aim of group decision support. 
Communication researchers have identified questioning as a means to promote relationships, form judgments, to manage conversations and to realise or diminish control (Krone 1993). Questioning permeates our talk, often without us being aware (Krone 1993). In the field of facilitated decision support, questioning is not a topic that receives a lot of attention, however, it has been acknowledged that questioning can be very influential. See for instance Richardson and Andersen (1995, p. 126) who discussed the teamwork required to support a group with group model building. They did not explicitly present questioning as essential to group facilitation, but noted: "We then asked the group what pressures these densities [ratios between variables] would generate (...). That question, repeated in many contexts as the workshop continued, proved incredible productive (...)". Various authors have paid attention to questioning in descriptions of roles, competences or practices of facilitators (Ackermann 1996; Franco and Montibeller 2010; McFadzean 2002; Phillips 2007; Vennix 1996; Wilkinson 2004). Vennix (1996, p. 149) for instance, stated that questioning is "one of the most powerful interventions for any facilitator which, if conducted properly, is not threatening to other people".

Indications have been given on the type of questions facilitators should ask. These all point to the nonprescriptive and nonthreatening nature of the facilitator's language. For instance, questions should be open (Nelson and McFadzean 1998) and nondirective (Franco and Montibeller 2010). Open questions will invite group members to give expanded answers (Schultz and Kushlis 2006). Nondirective questions enable facilitators to encourage further exploration of the topic of discussion while simultaneously refraining from giving a judgmental evaluation on its content. The latter is important to enhance group members' ownership of modelling results and commitment to action (Vennix 1996; Franco and Montibeller 2010). As discussed by Kim and Mauborgne (1998) to perceive a decision making process as fair positively affects individual attitudes such as trust, satisfaction, and commitment. Three ingredients are collectively needed to form procedural justice: It is necessary to realise engagement by asking individuals for input as well as providing the possibility to disagree and refute. Next, explanation is necessary to understand the final decision as well as why some ideas may not be included in the decision. Finally, it must be clear what is expected from those involved in decision making (Kim and Mauborgne 1998). We therefore can expect an effect of questioning on procedural justice: questions aimed at obtaining input foster engagement, questions may surface topics that need further explanation and questions can help to clarify expectations.

Ackermann (1996, p. 95) reported that clients appreciate that facilitators ask "difficult or sometimes obvious" questions. Such questions help to challenge assumptions and ideas, and stimulate the consideration of alternatives (Ackermann 1996). Especially this kind of questions need to be embedded in the attitudes of inquiry and neutrality as discussed by Vennix (1996). To clarify issues and prevent misunderstandings, the facilitator can pose difficult or obvious questions on topics that groups members tend to avoid, for instance, to save face.

To come to a useful typology for assessment of questions asked by discussion leaders in our study, we considered a variety of question characteristics, for instance, the form, function, or responses to questions (e.g., Stivers and Enfield 2010; Tracy and Robles 2009). We excluded characteristics implying evaluative comments (e.g., degree 
of difficulty of questions), as evaluation comes along with ambiguity. It is possible to imagine examples of difficult or sometimes obvious questions, but to identify a question as difficult or obvious requires understanding of the specific context at hand and the level of understanding of participants to which the question is posed. The form of a question (e.g., open as contrasting to polar; the latter leads to two possible answers such as yes or no; Stivers 2010) is more easy to identify in a valid way. Furthermore, in case of an open question, the form fits well to the discussion climate that facilitated modelling aims to create. Knowing that a question is open or polar, however, may be of limited value; the form does not indicate the action or function implied by the question. Consider for instance a question such as "How have market forces changed?" (asked in group 17 in this study). Such a question could have been identified as an open question and we could have assessed the extensiveness of contributions following the question. Yet, more interesting than length or extensiveness of replies seemed to be the task related function of questions in helping group members to reach a shared view on the problem, for instance by detecting relationships between problem elements or providing clarification. We believed that a classification of questions according to their function would contribute to a richer description of questioning by discussion leaders. We thus opted for a functional approach to assess the questions asked.

\section{Functions of Questioning by Discussion Leaders}

Following Simon (1976; see also Eden 1992) organisational behaviour can be called procedurally rational when an appropriate process has been followed. In our view, questions play an important role in a group decision making process. Questions can be used for various purposes; to invite, request, challenge, complain, exercise control and power, to name some of them (for more examples, see Tracy and Robles 2009). In this study, we are interested in the process of facilitation in decision support for groups with members having different perspectives on a strategic problem. In that context, we distinguished the following three main functions of asking questions by discussion leaders as most relevant: rational and social validation, prompting reflection, and information management. These functions form the main categories in the typology presented in Table 1 . Each category contains multiple question types, as will be described below.

\subsection{Rational and Social Validation}

An important function of questions by discussion leaders is to request and obtain information This function is reflected in the conventional definition of 'the question' by Heritage (2002, p. 1427 in Tracy and Robles 2009, p. 133): "a form of social action, designed to seek information and accomplished in a turn at talk by means of interrogative syntax". Information-seeking questions request information that is missing and is thought to be present in the group (Graesser and Person 1994). As problem owners have diverse sets of decision-relevant information, they come together to exchange individually owned information and integrate this into a shared view on the problem. In that context, specifically two types of questions can be asked by 


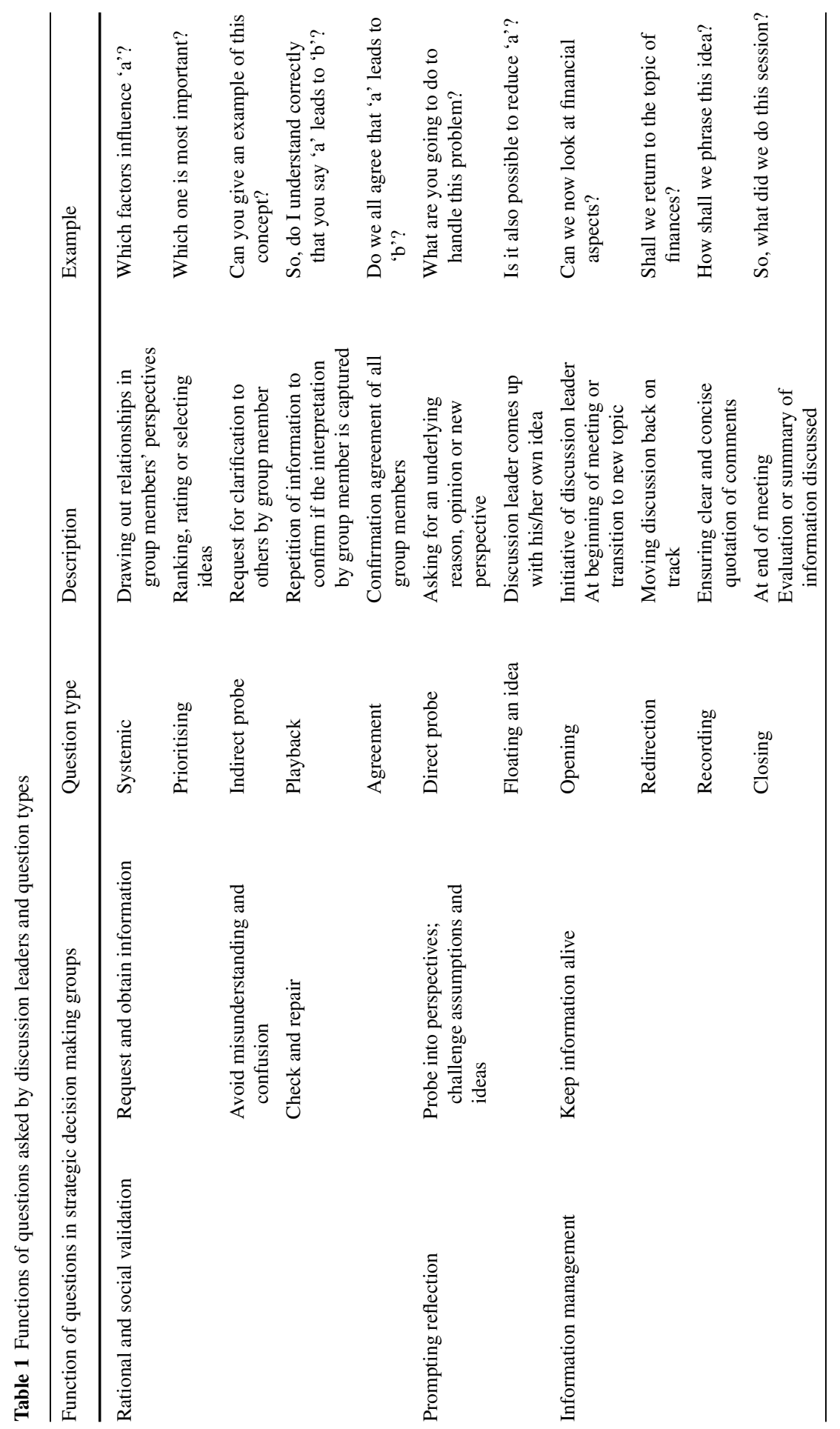


discussion leaders, that is, systemic and prioritising questions. Systemic questions aim to "draw out connections and relations" in participants' perspectives (Spano 2006, p. 280). This question type is useful to discover links and interaction between issues in the problem situation. The elicitation of information generally comes along with determining the relevance of information. It must be decided which items to work on further (Wilkinson 2004) or to include in the model. Prioritising questions can help participants to rank, rate or select ideas (Wilkinson 2004).

Further, questions can help to avoid misunderstandings and confusion. This is an important function of questions for groups experiencing a messy problem. As Cronin and Weingart (2007) argued, in groups of members having different knowledge and values, inconsistencies between group members' definitions of the group's problem hinder the integration of group members' information into a shared view. Cronin and Weingart call such inconsistencies representational gaps. Representational gaps are problematic because information on the problem will be interpreted and evaluated differently which can lead to conflict on how to jointly manage the problem situation. It is often difficult to detect the source of inconsistencies as group members may not be aware or think about the possibility that, for instance, their assumptions differ (Cronin and Weingart 2007). Yet, questions may help to recognise what unknown or unclear (Vennix 1996). By using indirect probes, the discussion leader can indicate that he or she-and maybe others in the group - fail(s) to understand what is said. So, indirect probes can help group members to clarify their contributions (Wilkinson 2004).

In the same vein, some questions of the discussion leader are meant to check for agreement and whether repair is needed. Interestingly, in spontaneous conversations involving two to five persons, this type of questions made up a considerable part of the total number of questions. In a sample of 328 questions, $31 \%$ questions initiated repairs and $21 \%$ requested confirmation (Stivers 2010). The check and repair function is particularly relevant in facilitated modelling given that the aim is to jointly build a model that is meaningful and appropriate. The creation of such a model requires that participants agree upon the meaning and inclusion of elements and relations in the model under construction. Therefore, contributions are continuously checked and clarified (Franco 2006; Vennix 1996). Considering the check and repair function of questioning by discussion leaders, we distinguished two question types. First, the discussion leader can hand information back to group members to create understanding or initiate repair with playback questions. In playback questions, the discussion leader may repeat a group member's contribution, or translate it into other words to clarify one's understanding (cf. Phillips 2007; Wilkinson 2004). Second, the discussion leader can use questions to check the agreement level in the group on what has been contributed.

Altogether, asking questions that seek information, clarification, check for agreements or initiate repair provide ways to elicit and integrate the contributions of stakeholders. By using these questions, discussion leaders promote a rational and simultaneously social validation group process. 


\subsection{Prompting Reflection}

Questions that encourage thought and participation are critical for effective facilitation (Clawson and Bostrom 1996). Based on an in-depth analysis of 235 reports from 50 experienced facilitators, questioning was raised as one of the sixteen critical facilitator role dimensions. The dimension not only regards the act of asking the "best" questions that encourage thought and participation, but also the development of questions (i.e., how to word questions) (Clawson and Bostrom 1996, p. 13). Direct probes are meant to challenge group members thinking and reasoning, for instance when the discussion leader has doubts about correctness of what was said by someone (Wilkinson 2004). Critical questions can be used to increasing cognitive conflict in the group. A critical question is particularly useful when the group seems to develop a premature consensus and more probing into the problem definition or perspectives is required (Vennix 1996). This helps to challenge assumptions and ideas, as part of the joint thinking process. Thus, the discussion leader can then use questions as a very direct way to stimulate the thinking process.

Another way to challenge participants may be to use the floating an idea question. In that case, the discussion leader gives a suggestion in the form of a question, such as "What about ....?" (Wilkinson 2004, p. 41). We see this as an interesting question type to include in our typology to assess the degree to which these questions have been used by discussion leaders. In facilitated modelling, the facilitator is expected to refrain from value judgements and expressing own opinions (Franco and Montibeller 2010; Vennix 1996). This stems from the idea that being actively involved in the content of the discussion hinders a discussion leader's capability to observe and reflect the process (Doyle and Straus 1976; Phillips and Phillips 1993). In the view of Phillips and Phillips, being actively concerned with the content of discussions or refraining from contributing to content, is the essential difference between leading and facilitating a group. However, there may be instances where contributing to the content of the discussion seems appropriate to facilitators (Vennix 1996). For instance, if the group seems to overlook potential relevant information (Wilkinson 2004). Then, there is the possibility to step out of the facilitating role for a moment to contribute the information (Doyle and Straus 1976). Alternatively, Wilkinson (2004) suggested to float the information in a question. (For an account of how facilitators might become involved in the discussion process, see Gregory and Romm 2001).

\subsection{Information Management}

Already half a century ago, Maier (1967) considered the unique role of discussion leaders to effectively use group resources and avoid potential dysfunctions. He argued that discussion leaders need to focus on the group process in a serving role, and take responsibility for accurate communication and managing information (Larson et al. 1998; Maier 1967). Keeping the discussion moving and summarising are just some of the concrete behavioural options mentioned by Maier for group leaders to facilitate a discussion. Information management is particularly important when different group 
members bring up related issues at different episodes of the discussion (Larson et al. 1998).

Discussion leaders influence the flow of discussion in various ways, for instance by inviting group members to elaborate on issues or avoiding superfluous detail (AksoyBurkert and König 2015). In groups guided by a chairperson, information management is however complicated by the dual role of the chairperson in the discussion (Keyton and Stallworth 2003; Phillips 2007). The chairperson faces the task of guiding the group towards achievement of the meeting goal, but typically also has a stake in the content of the discussion. The chairperson may want to come up with own information and opinions, rather than inviting other group members to contribute. In contrast, facilitators try to refrain from expressing their opinions. In facilitated modelling, keeping the discussion on track involves asking questions rather than voicing opinions. The questions are closely related to the modelling process (Vennix 1996). For instance, to start the modelling process in group model building, typically, the facilitator asks the group to identify the problem variable including the time horizon (Vennix 1996). The facilitator directs the group towards exploration and identification of the problematic behaviour of the problem. Subsequently, the facilitator asks the group members to identify causes and effects of the problem variable. Building the model is realised through asking questions (e.g., "which variable is a cause for change"?, "does everyone agree with [the proposed relation]?"). Active inquiry by discussion leaders will encourage group members to contribute to the discussion; being a discussion leader includes status and enables the discussion leader to influence the discussion process (Edmondson et al. 2003).

Information management through asking questions can lead to a better use of information in group decision making (Larson 2010; Okhuysen and Eisenhardt 2002). In an experiment in which three-person medical teams diagnosed fictitious cases, Larson et al. (1998) observed that the group leader asked more questions about information discussed earlier than the other group members. This behaviour was explained by the leader position in the group, as this position would include a greater responsibility to fulfil the information management function. Asking questions helps the group to not forget or overlook relevant information discussed at an earlier moment in the discussion. Thus, questioning is a way to keep information "alive" (Larson et al. 1998, p. 105).

The preceding has shown that questioning is part of information management. By selecting specific questions to ask to group members, discussion leaders influence the flow of the discussion and information use. We distinguished four question types as indicators of information management. Opening questions are questions that discussion leaders use at the start of the discussion or at the switch to a new topic in the discussion (called 'starting' questions by Wilkinson 2004). Redirection questions can be asked when group members contributions appear to go beyond what is seems relevant for the discussion at that moment. The function of these questions is to keep the discussion back on track (Wilkinson 2004). Further, discussion leaders need to keep track of the information that is discussed and synthesise the information (Nelson and McFadzean 1998). Group members' contributions should be recorded in such a way that group members understand them and feel committed to the content of information recorded (Wilkinson 2004). Recording questions therefore aim to ensure that what is 
documented during the discussion, reflects what participants have contributed (i.e., in their words). Finally, closing questions can be used at the end for reviewing and evaluating group members' objectives, the issues discussed and the results achieved (Wilkinson 2004).

In sum, three main arguments underlay our interest in questioning behaviour: the rational and social validation function, the prompt for reflection and, finally, the information management function. It should be noted that we focused on task-related questions in this study. In other words, we did not consider questions that could be considered as socio-emotional contributions.

Table 1 presents the typology that served to assess questioning by discussion leaders in this study.

Based on the foregoing descriptions and arguments, a major difference between chairpersons and facilitators is that the first also makes content statements while the latter refrains from taking a position on the issue the group works on. We thus assumed that a larger fraction of the contributions of the facilitator would be formulated in a neutral manner, for which a question is a useful format. Therefore we expected that in groups supported with group model building, more questions of all types would be asked by the discussion leader than in unsupported meetings.

\section{Method}

Below, we describe the classroom experiment in which we collected data for our study. Data were collected during a $\mathrm{PhD}$ project in which we evaluated the effectiveness of group model building (McCardle-Keurentjes 2015). As these data stem from discussions that were transcribed and coded, we specifically pay attention to our approach to coding. We first tested the difference in the total number of questions asked by discussion leaders in group model building groups versus unsupported groups (also called meeting as usual groups). We continued with a comparison of question type frequencies and sequences in questioning by discussion leaders. For the latter, we extended the work by Block (2016) that was supervised by the first author and used the dataset of McCardle-Keurentjes (2015).

\subsection{Participants and Design}

A total of 152 undergraduates (third year students in a Bachelor's programme in Business Administration) participated as part of their teaching program in an experiment of one factor (decision support) with two levels (group model building support vs unsupported). Students subscribed in small groups to participate in a session that was presented to them as an exercise in group decision making. The students were randomly assigned to the conditions. One group was dropped from the analysis because this group was incomplete. The data of 26 five-person groups were analysed. In each condition, 33 women and 32 men participated as a group member. The mean age of participants was 21.5 years $(n=130, S D=2.05)$. 


\subsection{Procedure and Decision Making Task}

The experiment was conducted over 2 days. For the experimental (group model building) groups, five facilitators were available. The facilitators were instructed to facilitate on the basis of their experience. One facilitator supported five groups, one facilitator supported three groups, two facilitators each supported two groups and there was one facilitator who supported one group. We asked the four facilitators who supported more than one group to try to start with each group from scratch (so, not to use the information that came up in a previous group discussion). We asked all facilitators to not discuss their experiences with colleague facilitators during the course of the experiment. The facilitators were not informed about the microlevel behaviour of our interest.

In the group model building groups, the facilitator guided the meeting, and took care of the experimental procedure (i.e., handed out materials such as consent subject forms and questionnaires). In the control (meeting as usual or unsupported) groups, a research assistant directed the procedure and handed out the materials. In both conditions, the task information was distributed to participants systematically (i.e., one after another, to start with the person at one's left). The fifth group member received information belonging to the role of 'president and board'. We expected this person to chair the meeting. This person thus combined the role of a group member and discussion leader. The meeting as usual groups were free in how to shape their meeting.

The participants received a hidden profile task based on a real-life strategic decisionmaking problem, that is, the case of the Saturday Evening Post (Hall 1984), once a magazine in the United States. There were five managers in the team, each belonging to different departments, that is, circulation, publisher, editorial, production, and president and board (i.e., the office of the president representing the board). In addition to the general information for all, each manager received information that was particular to his/her position. The team was instructed to clarify the problem of falling profits and asked what to do to tackle the problem. Three options were proposed to consider, but other options could be also considered. The participants were allowed to review their task information during the discussion, but not to read it out loud to other group members.

All groups had one hour for the decision making discussion, and all discussions were video and audio recorded.

\subsection{Coding}

The videotapes of the recorded discussions $(N=26)$ were transcribed by students/research assistants who were not informed about our research aim. We left the notation of question marks in the transcript to the natural language interpretation of each transcriber. We ensured the adequacy of the transcriptions in several ways, for instance, with a written instruction, and by checking parts of the transcribed materials.

For coding the data, first, we determined the unit of observation (Weingart 1997). Each sentence was considered a separate unit for coding, because that allowed us to assign codes to each—easy to identify—part in a speaking turn, as well as to 
Table 2 Sample of a coded transcript of a group model building discussion

\begin{tabular}{ll}
\hline Role $^{\mathrm{a}}$ and contribution & Code (explanation) \\
\hline Pu Well in general the more readers the more profit & PU_LZ (publisher, readers) \\
& PU_WI (publisher, profits) \\
Ci Yeah sure, sure & CI_SR (circulation, simple reaction) \\
Pu If you lower subscription price, you have more & PU_ABP (publisher, subscription \\
profit & price) PU_WI (publisher, profits) \\
Fac Okay, we can always change the model later. & FAC (facilitator) \\
$\begin{array}{l}\text { This is.. it's the first thing, this readers profit, } \\
\text { readers goes up, the profit goes up. But it had }\end{array}$ & FAC (facilitator) \\
also had to do with price I heard? & FAC_Q (facilitator, question) \\
\hline
\end{tabular}

${ }^{\text {a }}$ Roles were typed in bold in the transcript

interruptions in a speaking turn. Next, we constructed a task-specific coding scheme to include the categories of the variables of our interest. Using the software program ATLAS-TI, for each unit we identified the speaker and whether the contribution was a question or not. The presence of a question mark at the end of a sentence sufficed to consider the unit as a question. Further, all contributions of group members-but not of the facilitator-were assessed with regard to the content of the contribution. The coding scheme and instructions were included in a codebook.

To determine the specific content of contributions required considerable coding training. Yet, the coders could easily identify the speaker and form of a contribution from the transcript: The role name of the participant or of the facilitator was visible in the left margin. Also, it was visible whether a contribution was accompanied by a question mark. As an example, a short extract of a transcript and the codes that are assigned, can be seen in Table 2. In this part of the discussion, the publisher and the circulation manager are contributing, and the facilitator reacts to them. It shows, for instance, that the last contribution of the facilitator is a question, and is coded as FAC_Q (i.e., facilitator_question). Note, if the contribution of the facilitator would not have been accompanied by a question mark in the transcript, only the role code of the facilitator would have been be assigned. The sample also shows group members' contributions, such as the first unit in which the publisher (PU) contributed to the discussion and to which two content codes were assigned, that is, readers (LZ), and profits (WI).

The final intercoder reliability values were $\kappa=.67$ (unsupported discussions) and $\kappa=.73$ (group model building discussions). Both values were above the threshold suggested by (Neuendorf 2011) and could be considered "acceptable" and as "good" agreement (Fleiss et al. 2003, p. 604), respectively. It should be noted that these values are primarily meaningful with regard to the reliability of the coding concerning the content of the contributions of participants. As said before, it was fairly straightforward to identify the person who was talking as well as whether a contribution was a question or not.

The number of questions asked was assessed per group discussion. As the number of questions asked is dependent on the length of the discussion, we determined the ratio of questions asked by the discussion leader to the total contributions made in 
the discussion. This ratio was used to test the difference in questions asked by the discussion leader in the two conditions.

To compare the type of questions asked by discussion leaders and the sequences in questioning over time, the 26 transcripts of group discussions were recoded. Initial coding focused only on identification of question types resulting in frequencies (Block 2016). On the basis of Block's work, functions were grouped into categories (see Table 1) and sequences were identified. Again, coding instructions were used as well as the programme ATLAS-ti. We identified all sentences ending with a question mark as a unit and coded these with respect to question type. Sentences in which the discussion leader expressed that he or she was asking — or wanting to ask - a question were also selected for coding (this is different from the coding reported above where we only coded units as a question if they were accompanied by a question mark). We took account of the context of questions to determine question type with the restriction of a domain up to and including ten units (i.e., sentences) before and four units after the question to code. We assigned questions that did not match to one of the question types, to a separate category 'Others'. Some examples of questions in this category are "Sorry?", "Actually, it is going well, isn't it?", "What time is it?".

Before the final coding started, the coding was practiced. We compiled four documents of various discussion parts for comparison of coding work by two coders. The coders discussed the disagreements in coding which resulted in adaptation of the coding instructions. One change in the codebook was the inclusion of a simple decision scheme. A question could be assigned into only one category and in some cases it was difficult to decide which question type was most applicable. We therefore designed the decision scheme to indicate an ordering of question types (see Fig. 1). First, we considered whether the question was an opening question, redirection or closing question (all three belonging to the information management category). In Fig. 1, these are captured under 'procedural' questions. If the question was not a procedural questions, the coder assessed whether the question could be identified as one of the questions listed in the right column. The right column lists question types (summarised as 'problem structuring' questions) that seemed to be more directly related to functions affecting the climate necessary to gain insight into the problem and to come to a joint group answer in the problem situation.

The final coding was performed by one person, but a second coder was involved to assess reliability of the final coding. To determine reliability of this coding, we considered the general rule with regard to the size of a sample for testing reliability provided by Neuendorf (2002), which says that probably 50 units should be needed minimally, and more than 300 units rarely. We opted for 100 units from group model building discussions and 100 units from the discussions in unsupported groups. We randomly selected parts from both groups and from different parts in the discussion. The reliability values were $\kappa=.81$ (group model building discussions) and $\kappa=.74$ (unsupported groups), which could be considered as fair to good (Fleiss et al. 2003). 


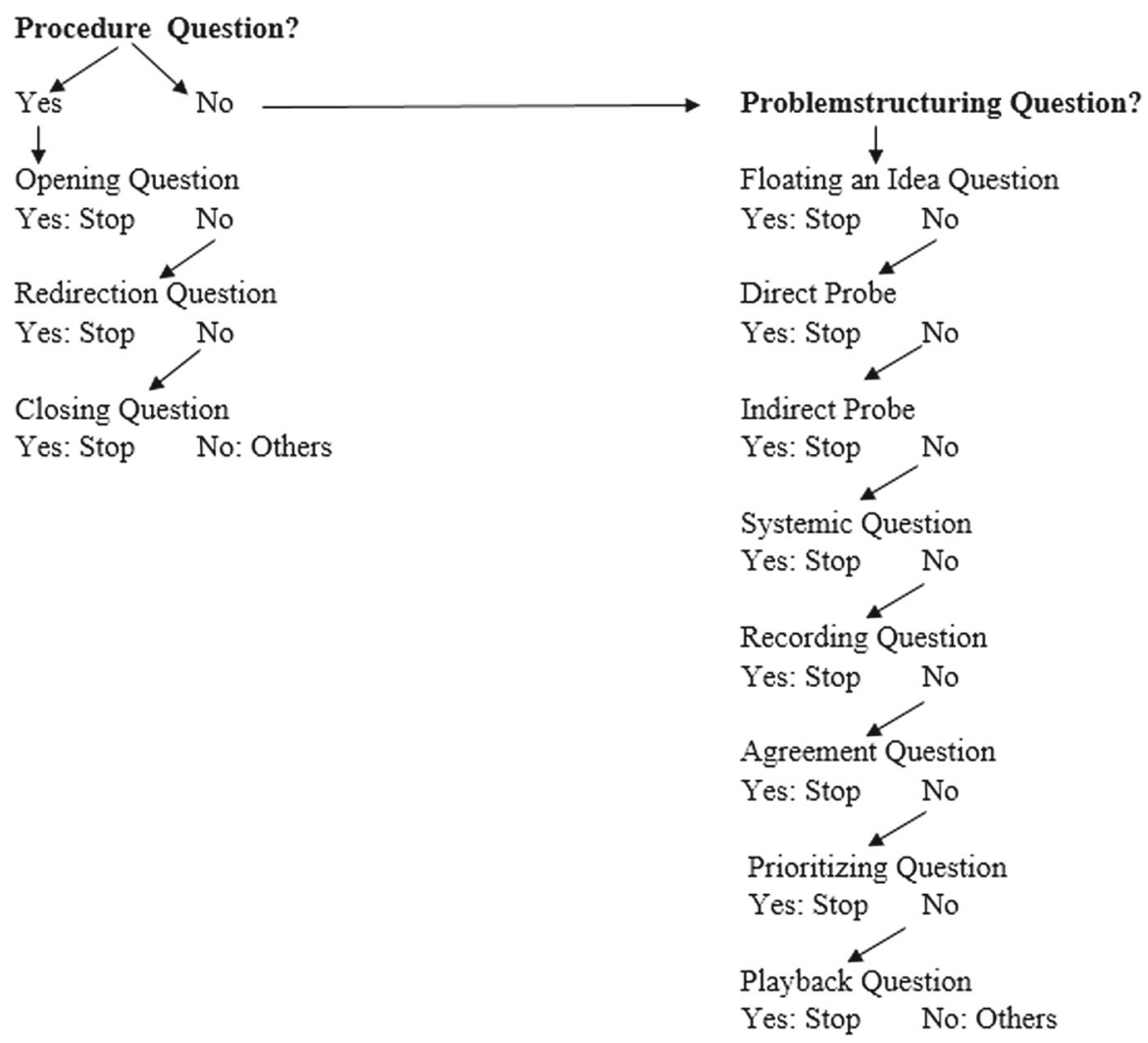

Fig. 1 Decision scheme for coding question types (reproduced from Block 2016, p. 26)

\section{Results}

In this section we first report findings with respect to the total number of questions asked by discussions leaders in the two conditions. Next, we address the results on question type frequencies and sequences of questions over time.

\subsection{Frequencies}

In total, 24,452 contributions were identified in the discussions $(N=26){ }^{2}$ In the group model building condition, 12,571 contributions were made (from both participants and facilitator), and in the unsupported condition, 11,881 contributions were made (McCardle-Keurentjes 2015). From the contributions of facilitators in group model building discussions, $34 \%$ were questions (total contributions of facilitator: 4671 ). The percentage of questions in chairpersons' contributions was $13.3 \%$ (total contributions of chairpersons: 3137$)$.

$\overline{2}$ Excluded contributions $(n=280)$ of which the source was a research assistant, an observer or unclear. 
Please recall that we took into account that the number questions asked by discussion leaders is related to the length of discussions and that we determined questioning behaviour of the discussion leader as the ratio of questions asked by the discussion leader to the total number of contributions made in the discussion. The median percentage of questions asked by the discussion leader in the unsupported groups (i.e., the chairperson) was 3.34 with a range of 8.30 . The median percentage of questions asked by facilitators was 14.27 with a range of 13.45 (McCardle-Keurentjes 2015).

We expected that more questions would be asked by the discussion leader in groups supported with group model building than in unsupported meetings. A Mann-Whitney $U$ test indicated that the facilitator in group model building groups (Mean Rank $=16.75, n=13$ ) asked more questions than the chairperson in the groups without decision support (Mean Rank =7.46, $n=13$ ), $U=6.00, z=-3.33$ (corrected for ties), $p<.001$ (one-tailed). ${ }^{3}$ This could be considered a "large" effect size $(r=.80)$ and supported our expectation (McCardle-Keurentjes 2015).

We now turn to the measures and results with regard to our examination of question type frequencies and sequences. Table 3 shows the frequencies of questions per type for each discussion in our sample. The questions are sorted in the main categories of functions of questions in group decision making (i.e., rational and social validation, prompting reflection, and information management) and a category Others.

As questions were not normally distributed, we used a nonparametric test for differences in medians. Fisher's exact probability test showed that looking at absolute numbers, group model building discussions had a higher median number of all question types than unsupported discussions (highest two-tailed significance was .001 which is significant at the .05 level). However, since the total number of questions identified was higher in group model building discussions than in unsupported discussions (column Quest Total), it was also useful to look at the fraction of questions of each type out of the total. Fisher's exact probability test for relative numbers showed that, compared to unsupported discussions, group model building discussions had a higher fraction of questions of the types social and rational validation and prompting reflection (two-tailed significance was .02 which is significant at the .05 level). The fraction of questions on information management and others was not significantly different (two-tailed significance was .43).

\subsection{Sequences}

Before we address patterns in sequences over time, a couple of observations are important. First, it is important to remember that we only looked at questions by the discussion leader: the facilitator in the case of group model building and the chairperson in the case of unsupported groups. For participants in a group model building session, the approach to be followed is novel. This means that the steps in the process

\footnotetext{
3 A Kolmogorov-Smirnov test for two independent samples showed that the cumulative distributions were different, and supported the results of the Mann-Whitney $U$ test; the percentages of questions asked by the discussion leader in group model building groups were higher than in the unsupported groups; the difference was statistically significant, the most extreme absolute difference $D=.77, Z=1.96, p<.001$, one-tailed, exact probability.
} 


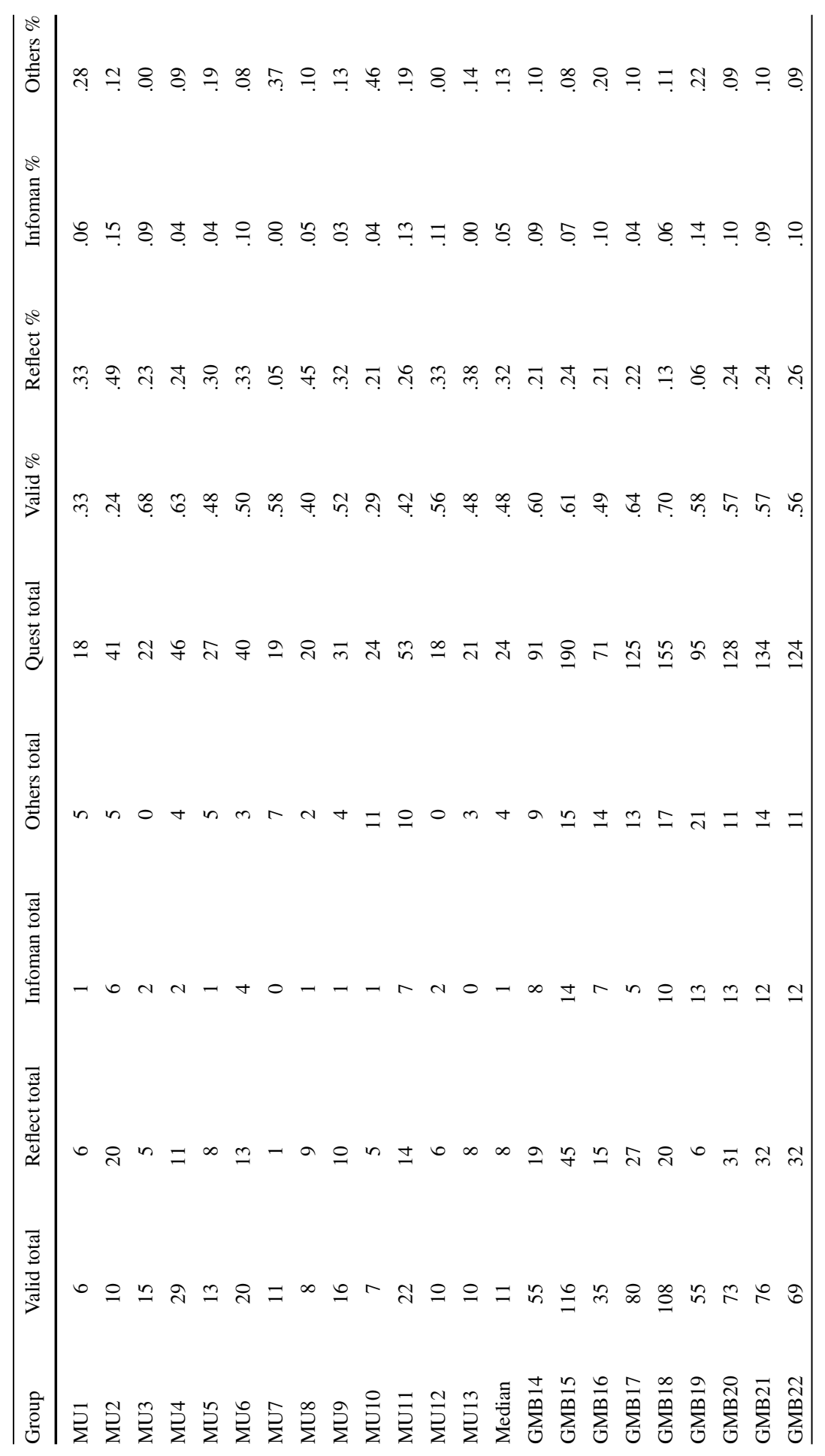




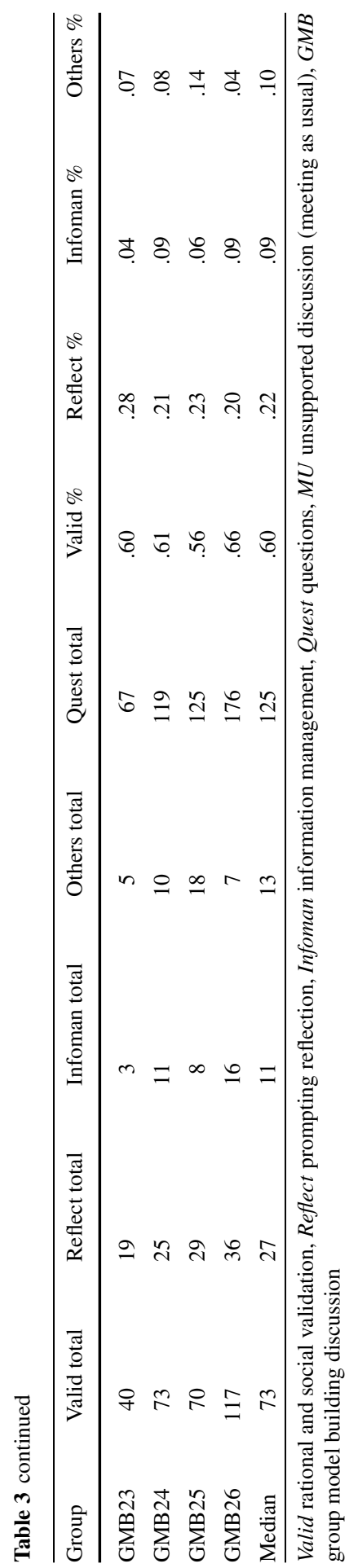


and the type of information sought after is not familiar to group members. Contrast this to the unsupported meeting, in which the chairperson employs a procedure that is at least somewhat familiar to all participants in the group. As a consequence, participants in a unsupported meeting may find it easy to take over the task of the chairperson. If, for example, the chairperson asks for options to improve the situation of Saturday Evening Post, this question does not need extra explanation and should the occasion arise, a group member will find it easy to prompt for further actions. In that case, the group member takes over part of the questioning role of the chairperson. For group model building this is less likely as facilitator questions are novel to participants. Questions include for instance: "Which variables can you think of that relate to this problem?" or "Is A related to B?". The concept 'variable' and the exact meaning of 'relationship' is novel to most participants, making it less likely that group members take over this role of the facilitator. This may lead to the expectation that in group model building most questions are asked by the facilitator, while in unsupported meetings questions are more equally shared by the chairperson and participants. However, this turned out not to be the case (McCardle-Keurentjes 2015); the difference between the number of questions asked by group members in the two conditions was nonsignificant.

Second, a group model building meeting proceeds through a series of well-defined steps but this is not true for meetings as usual. Participants in group model building work on their task by following the phases of NGT, linking variables by drawing causal relations, and identification of options to improve the situation. The phases of divergence and convergence are thus intentionally separated and the discussion starts with problem analysis before moving on to discussing solutions (Dwyer and Stave 2008; Franco et al. 2016). In unsupported discussions we can expect a more fluid process without clearly separated phases. The chairperson may open the meeting by inviting each participant to state their preferred solutions, after which a discussion emerges on the rationale for each solution. Alternatively, the chairperson may propose to analyse the problem before going to solutions (see also Hirokawa 1983). In other words, the order in which the problem and solutions is discussed may vary. Meetings as usual, using open discussions, are notorious for diving into one particular aspect of the issue without keeping the bigger picture in mind (the bandwagon effect; Doyle and Straus 1976). This means that divergence and convergence are mixed up.

The fact that, in comparison to a chairperson, the facilitator's role is less easily taken over by participants, combined with the observation that group model building process is more clearly separated in steps than meetings as usual, has a number of consequences for sequences over time. The first is that the facilitator will have a bigger role in guiding participants through the process than the chairperson. When the group needs to switch from NGT to identifying causal relations, the facilitator needs to describe what is expected and explain the rationale for moving to the next step. This involves questions on closing one task (e.g., "I would like to propose we stop adding variables for the moment. Does this list of variables cover the most important aspects of the problem?") and opening or introducing the next task (e.g., "We can now have a look at how problem elements are interconnected. Is everyone fine with switching to identifying relations?"). Therefore it seems logical to expect more information management questions around the transition of phases. But information management can also be expected while working on a task. The middle part of the process, causal 
mapping, typically takes more time than NGT or identification of policies. When the group has spent some time on causal analysis of one part of the problem, let's say marketing, he or she may ask the group if there are other important dimensions. This may take the form of an opening question, for instance "Can we now look at financial aspects?". Therefore we can expect 'spikes' of information management in between steps but also during the phase of causal mapping.

The fact that group model building is organised in distinct steps, and in particular that divergence and convergence are separated, has another consequence. NGT is a divergent step that prompts group members to generate information, which primarily relates to rational and social validation. Where NGT prompts for variables, the next step of causal diagramming asks for relations between variables. This continues rational and social validation but also goes into reflection: Having information on the board for all group members to see, makes it easy for the facilitator to invite participants to reflect on what has been captured so far. In turn, this can extend into identification of policies. Once the causal structure of the issue is visualised, the facilitator can turn the discussion to steering the problem in the right direction (e.g., "Is it also possible to reduce 'a'?").

This led us to the following patterns that could be observed in the sequences over time. In group model building we would expect to see episodes of information management when moving from one step to another and in the middle step of causal mapping. In unsupported groups this would be less the case as steps are not clearly separated. In group model building we expected rational and social validation in the beginning of the process, giving way to reflection. Again, in unsupported groups we expected a less clear development over time.

The graphs in Fig. 2a, b can be read as follows. The horizontal axis shows time. The duration of the meetings varied both within and between conditions. The median time for unsupported groups was $52 \mathrm{~min}$ with a range of $40 \mathrm{~min}$. The shortest unsupported meeting lasted for 29 and the longest for $69 \mathrm{~min}$. The median time for modelling groups was 62 min with a range of 20 min. The shortest group model building meeting took 50 and the longest $70 \mathrm{~min}$. A Kolmogorov-Smirnov test for two independent samples showed that the difference was significant (most extreme absolute difference $D=.54, Z$ $=1.37, p=.04$, two-tailed, McCardle-Keurentjes 2015). Because of the large variation in the duration of discussions, we opted for standardising the time axis by dividing each discussion in ten phases. The vertical axis indicates for each phase the absolute number of three types of discussion leader questions (rational and social validation, prompting reflection, information management) and of questions in the category others. Note that the vertical axis for unsupported groups has a range from 0 to 10 and for the modelling groups from 0 to 20 .

Visual inspection of the graphs revealed first and foremost the great diversity in questioning patterns over time. Looking at the sequences for group model building, some information management took place at the beginning of the sessions and in the middle phase. In unsupported groups, information management primarily happened at the end of the meetings.

Inspection of the group model building sequences also seemed to indicate that rational and social validation was high early on in the process and then declined over time. Conversely, prompting reflection was low in the beginning and increased over 

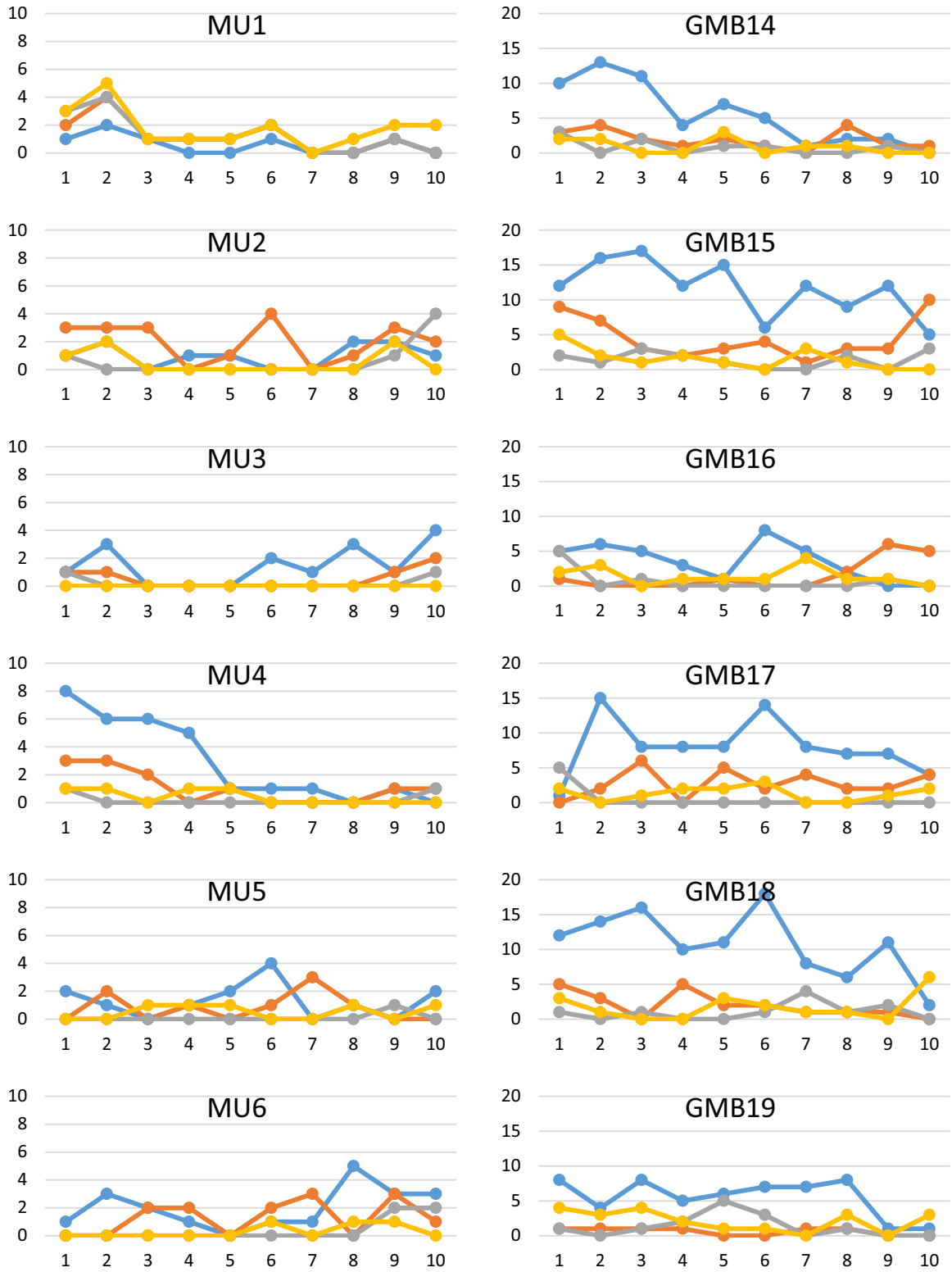

Fig. 2 a Sequences over time for unsupported (MU) groups 1-6 and group model building (GMB) groups 14-19. b Sequences over time for unsupported (MU) groups 7-13 and group model building (GMB) groups 20-26 (blue: rational and social validation; red: prompting reflection; grey: information management; yellow: others). Note: The $\mathrm{y}$-axis for MU groups has a range from 0 to 10 and for the GMB groups from 0 to 20. (Color figure online)

time. Considering the sequences of rational and social validation questions in the unsupported groups, a more ambiguous picture emerged. In some groups the chairperson asked validation questions primarily in beginning of the discussion (e.g., MU4, 

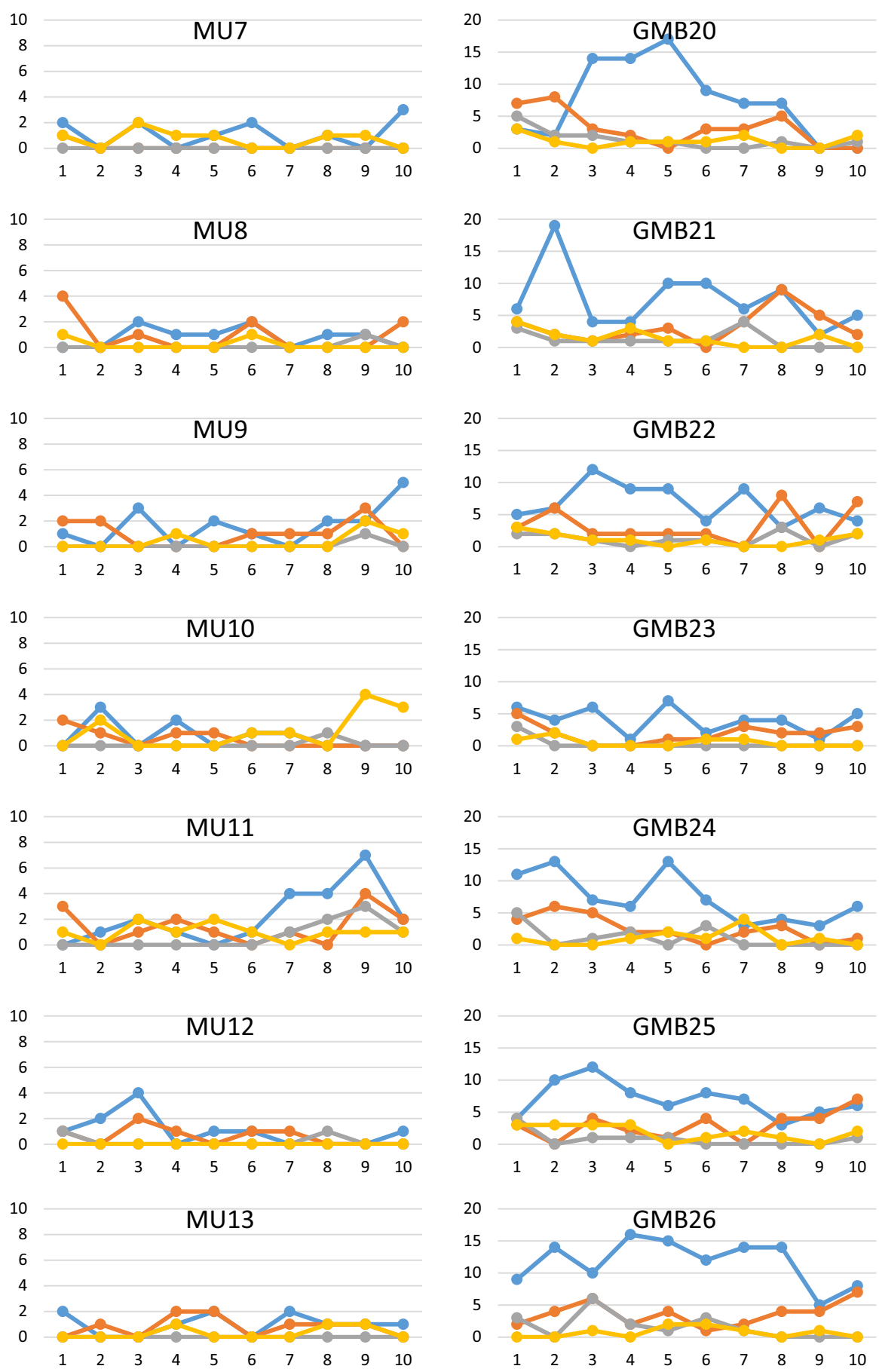

Fig. 2 continued 
MU12), others used these questions more in the second part of their meeting (e.g., MU 3 , MU11), and some others asked validation questions throughout the discussion process (e.g., MU7, MU9). Similarly, there seemed no pattern apparent in the sequence of questions asked by chairpersons prompting reflection.

Finally, with the exception of two unsupported discussions, questions of the category 'Others' were asked by all discussion leaders. These questions were asked at various moments of the process in both groups.

\section{Conclusion and Discussion}

As facilitator behavior can have great impact on groups (cf. Schein 1997), it is important to better understand how facilitators influence discussion processes. To that end, the present study explored a process element of facilitated modelling in a classroom experiment: question asking by facilitators. This study responds to the call for more systematic research on what actually happens in the process of facilitated modelling. We examined questioning behavior at the microlevel by comparing frequencies as well as sequences in which questions of different types were asked by the discussion leaders over time. The groups in our experiment were either supported by a facilitator using group model building, or guided by a chairperson who also had a stake in the problem the group worked on.

In line with our expectations, we found that in groups supported with group model building, more questions were asked by the discussion leader than in unsupported meetings. This finding extends the literature by showing for the first time that discussion leaders in facilitated modelling behave differently with respect to questioning than discussion leaders in unsupported meetings. Our study indicates that asking questions is a distinctive element of facilitation to support strategic decision making groups.

To further clarify questioning behaviour in our study, we presented a typology of questions based on functions of questions in strategic decision making groups. The typology contains three main functions of questions by discussion leaders: to (a) promote a rational and simultaneously social validation group process, (b) prompt reflection, and (c) manage information. This typology of questions was the basis for coding the questions of discussion leaders.

As expected, facilitators asked more questions of all functions than chairpersons (looking at absolute numbers of questions asked). This supports the idea that chairpersons are less likely to ask questions to group members due to their dual role in the discussion (Keyton and Stallworth 2003). In terms of percentage (taking into account the higher number of questions in group model building discussions), facilitators asked more questions than chairpersons to promote validation and stimulate reflection, but not to manage information. A clear conclusion can be drawn from facilitators' use of validation and reflection questions in our study: Asking questions that seek information, clarify and connect group members' contributions in a joint thinking process is at the very heart of facilitation in model-driven decision support. The evidence from our study supports assumptions about essential elements of facilitated modelling (see e.g., Franco and Montibeller 2010; Morton et al. 2003). 
The fact that there was no difference in the attention of discussion leaders for information management is unexpected and requires further consideration. One explanation may be that that the chairpersons tended to discuss one of the questions on the postdiscussion questionnaire (handed out for research purposes) more explicitly than the facilitators. If this question was discussed, obviously at the end of the meeting, it was coded as a closing question (belonging to the information management category). The lack of any meaningful difference in information management questioning may be due to the research design.

When we compared sequences in question types over time, we discovered patterns that differed widely in conditions and between conditions. Yet, there seemed to be some evidence for more a structured questioning process in group model building discussions compared to the discussions in unsupported groups. Analysis of question type frequencies revealed that facilitators mainly asked questions from the rational and social validation category, and that this question type declined over the course of the discussion process. Questions prompting reflection gradually appeared, and increased in number. In contrast, questioning behaviour of chairpersons showed a mixed picture for both rational and social validation questions and questions to prompt reflection. This seems to reflect the mixing up of divergent and convergent group activities which has been observed in unsupported groups (Doyle and Straus 1976). We believe that the sequences of facilitators' questions observed in our study show evidence of the nature of the process to realise the open climate necessary to build understanding. A climate for open discussion will be enhanced by questions that promote validation and support the thinking process (Vennix 1996). As questions are a way to support groups in a way that does not evoke affective or negative reactions (Bales 2002), facilitators may have used questioning as an intervention to help reaching the goals of group model building. We do not know whether facilitators used questioning intentionally as an intervention to better support their groups. Future work may build an understanding of the extent in which awareness by facilitators of questioning as an intervention (Schein 1997) is desired to improve the effectiveness of facilitated modelling in messy problem situation.

We hope the typology of question types developed in our study raises awareness of questioning as an intervention. The typology provides discussion leaders a preliminary overview of questions types related to their functions. Our typology does not include a separate category related to "difficult and sometimes obvious questions" (Ackermann 1996, p. 75), which derive their significance from the meaning in a particular context. However, difficult or obvious questions may be recognised within our typology: A direct probe is a critical question challenging group members' thinking, which can be perceived as a difficult one. Similarly, an indirect probe may be perceived as an obvious question, yet it may be needed to clarify a contribution and prevent misunderstanding. As said, we consider our typology as a preliminary overview; recognising that a better understanding of the relationships between questioning and outcomes of facilitated modelling is needed, it is likely that the typology will be adapted. So far, the current overview may be useful for novice facilitators to evaluate facilitation practices, and be stored in scripts (Hovmand et al. 2012). Furthermore, the typology can be helpful for educational purposes and training of skills (cf. Aksoy-Burkert and König 2015). 
The present study has several limitations. One limitation is inherent to assessment of frequencies of questions. Consider for instance the fact that information management questions were least often asked by discussion leaders (as can be seen in Table 3). While thinking about implications of the latter, the limitation of assessment of frequencies of questions - as in our study - becomes very clear: Frequencies are just a small part of the story, as one question will be more influential than another. Implicitly, the point has been made by Richardson and Andersen too (1995; see Sect. 3). We believe that additional qualitative analysis of questioning is a fruitful way to deepen our understanding of the role of questioning.

Further, in group interaction, a question never stands alone. A better understanding of the role of questioning by the facilitator will thus require more attention to the context; to what precedes a facilitator's question, and what is following it. For coding, this implies that we should focus on a larger part of the discussions than is done in this study. Moreover, social-emotional aspects in group communication should be examined too. Questioning entails more than what is asked, how often, and when; it is also about how questions are asked (Clawson and Bostrom 1996). In the present study we focused only on task-related functions of questions and neglected the importance of building and maintaining good relationships between group members (cf. Bales 2002).

The design of the study allowed us to examine our expectations, but especially the external validity is a point of concern. Our study was done in a classroom-setting with students working on a decision making task that they received from us. They did not work on their own problem (cf. Eden 1995). Discussion leaders in the unsupported groups were assigned a task they did not prepare for. Moreover, the chairpersons may have differed in their experience in guiding a discussion. From the perspective from participants, it may make a difference whether the discussion process is guided by a person who is external to their group (as the facilitators in our study) or by a student participant. Further, there are factors that we did not measure but may have played a role such as leadership style, status, or familiarity between group members. Another concern is that some facilitators guided more than one group. The information shared in one group may have influenced questioning by these facilitators in a subsequent facilitated meeting. We intended to minimise that influence from a previous session by asking facilitators to try to start from scratch with each group, but this may have been difficult to realise for them. The factors discussed so far point to potentially confounding factors in our study. Consequently, research on questioning in natural situations, both in supported as unsupported meetings, needs to be done. For an example of a study that investigated microlevel behaviour in facilitated modelling in a real-life setting, see Tavella and Franco (2015). Another concern relevant to external validity is whether our results can be generalised to other types of interventions. In our study we used one version of facilitated modelling: group model building resulting in qualitative causal loop diagrams. Although there are indications of similarities between the process followed in different approaches focused on qualitative causal modelling (see Herrera et al. 2016; Rouwette et al. 2011), this assumption remains to be tested.

Finally, Hirokawa (1983) found no relation between discussion process and effectiveness. McCardle-Keurentjes (2015) studied the process as well as effectiveness of group model building but did not analyse the link between the two. We have not con- 
sidered the effectiveness of groups in the present study. However, we have set a first step in shedding light on how questioning in facilitated modelling works. In this study, many questions were used by the facilitators in conversation with participants. In fact, $34 \%$ of the facilitators' contributions were coded as questions. Thus, questioning was an indispensable part of facilitation. Future studies should focus on identification of major patterns in question sequences, typical for facilitation, and their value for reaching the aims of decision support. Similar to discovering what is necessary to win a game of chess, we should identify facilitation strategies that work.

Acknowledgements The authors thank Isabel Block for her contribution in the development of the typology of questions, and the coding work to identify the occurrence of question types.

Open Access This article is distributed under the terms of the Creative Commons Attribution 4.0 International License (http://creativecommons.org/licenses/by/4.0/), which permits unrestricted use, distribution, and reproduction in any medium, provided you give appropriate credit to the original author(s) and the source, provide a link to the Creative Commons license, and indicate if changes were made.

\section{References}

Ackermann F (1996) Participants' perceptions on the role of facilitators using group decision support systems. Group Decis Negot 5:93-112. https://doi.org/10.1007/bf02404178

Ackermann F, Andersen DF, Eden C, Richardson GP (2010) Using a group decision support system to add value to group model building. Syst Dyn Rev 26:335-346. https://doi.org/10.1002/sdr.444

Ackoff RL (1979) The future of operational research is past. J Oper Res Soc 30:93-104. https://doi.org/10. $2307 / 3009290$

Aksoy-Burkert F, König CJ (2015) Meeting training: a suggestion. In: Allen JA, Lehmann-Willenbrock N, Rogelberg SG (eds) The Cambridge handbook of meeting science. Cambridge University Press, New York, pp 69-89

Andersen DF, Vennix JAM, Richardson GP, Rouwette EAJA (2007) Group model building: problem structuring, policy simulation and decision support. J Oper Res Soc 58:691-694. https://doi.org/10.1057/ palgrave.jors. 2602339

Bales RF (1951) Interaction process analysis: a method for the study of small groups. Addison-Wesley, Cambridge, MA

Bales RF (2002) Social interaction systems: theory and measurement. Transaction, New Brunswick

Beck SJ, Keyton J (2009) Perceiving strategic meeting interaction. Small Group Res 40:223-246. https:// doi.org/10.1177/1046496408330084

Black LJ, Andersen DF (2012) Using visual representations as boundary objects to resolve conflict in collaborative model-building approaches. Syst Res Behav Sci 29:194-208. https://doi.org/10.1002/ sres. 2106

Bleijenbergh I, Korzilius H, Verschuren P (2011) Methodological criteria for the internal validity and utility of practice oriented research. Qual Quant 45:145-156. https://doi.org/10.1007/s11135-010-9361-5

Block I (2016) Asking the right questions: Wat voor type vragen stelt een facilitator in group model building besluitvormingsgroepen? Bachelor in Business Administration. Radboud University, Nijmegen

Brocklesby J (2016) The what, the why and the how of behavioural operational research-an invitation to potential sceptics. Eur J Oper Res 249:796-805. https://doi.org/10.1016/j.ejor.2015.09.034

Clawson VK, Bostrom RP (1996) Research-driven facilitation training for computer-supported environments. Group Decis Negot 5:7-29. https://doi.org/10.1007/BF02404174

Cronin MA, Weingart LR (2007) Representational gaps, information processing, and conflict in functionally diverse teams. Acad Manag Rev 32:761-773. https://doi.org/10.5465/AMR.2007.25275511

de Gooyert V, Rouwette E, van Kranenburg H, Freeman E, van Breen H (2016) Sustainability transition dynamics: towards overcoming policy resistance. Technol Forecast Soc Chang 111:135-145. https:// doi.org/10.1016/j.techfore.2016.06.019

Dean JW, Sharfman MP (1996) Does decision process matter? A study of strategic decisionmaking effectiveness. Acad Manage J 39:368-396. https://doi.org/10.2307/256784 
Doyle M, Straus D (1976) How to make meetings work. Jove Books, New York

Dwyer M, Stave K (2008) Group model building wins: the results of a comparative analysis. In: The 26th international conference of the System Dynamics Society, Athens, Greece, pp 1-17

Eden C (1992) A framework for thinking about group decision support systems (GDSS). Group Decis Negot 1:199-218. https://doi.org/10.1007/BF00126263

Eden C (1995) On evaluating the performance of 'wide-band' GDSSs. Eur J Oper Res 81:302-311. https:/ /doi.org/10.1016/0377-2217(93)E0241-O

Eden C, Ackermann F (1996) "Horses for courses": a stakeholder approach to the evaluation of GDSSs. Group Decis Negot 5:501-519. https://doi.org/10.1007/BF02404647

Edmondson AC, Roberto MA, Watkins MD (2003) A dynamic model of top management team effectiveness: managing unstructured task streams. Leadersh Quart 14:297-325. https://doi.org/10.1016/ s1048-9843(03)00021-3

Finlay PN (1998) On evaluating the performance of GSS: furthering the debate. Eur J Oper Res 107:193-201. https://doi.org/10.1016/S0377-2217(97)00177-X

Fleiss JL, Levin B, Paik MC (2003) Statistical methods for rates and proportions Wiley series in probability and statistics, 3rd edn. Wiley, Hoboken

Forrester JW (1968) Market growth as influenced by capital investment. Ind Manage Rev 9:83

Franco LA (2006) Forms of conversation and problem structuring methods: a conceptual development. J Oper Res Soc 57:813-821. https://doi.org/10.1057/palgrave.jors.2602169

Franco LA, Montibeller G (2010) Facilitated modelling in operational research. Eur J Oper Res 205:489-500. https://doi.org/10.1016/j.ejor.2009.09.030

Franco LA, Rouwette E, Korzilius H (2016) Different paths to consensus? The impact of need for closure on model-supported group conflict management. Eur J Oper Res 249:878-889. https://doi.org/10.1016/ j.ejor.2015.06.056

Graesser AC, Person NK (1994) Question asking during tutoring. Am Educ Res J 31:104-137. https://doi. org/10.3102/00028312031001104

Gregory WJ, Romm NRA (2001) Critical facilitation: learning through intervention in group processes. Manage Learn 32:453-467. https://doi.org/10.1177/1350507601324003

Gunnarsson M (2006) Group decision-making: language and interaction. Ph.D., Göteborg University

Hackman JR, Morris CG (1975) Group tasks, group interaction process, and group performance effectiveness: a review and proposed integration. In: Leonard B (ed) Advances in experimental social psychology, vol 8. Academic Press, New York, pp 45-99. https://doi.org/10.1016/S00652601(08)60248-8

Hall RI (1984) The natural logic of management policy making: its implications for the survival of an organization. Manage Sci 30:905-927. https://doi.org/10.1287/mnsc.30.8.905

Hämäläinen RP, Luoma J, Saarinen E (2013) On the importance of behavioral operational research: the case of understanding and communicating about dynamic systems. Eur J Oper Res 228:623-634. https:// doi.org/10.1016/j.ejor.2013.02.001

Hawkins K, Power CB (1999) Gender differences in questions asked during small desicion-making group discussions. Small Group Res 30:235-256. https://doi.org/10.1177/104649649903000205

Herrera HJ, McCardle-Keurentjes MHF, Videira N (2016) Evaluating facilitated modelling processes and outcomes: an experiment comparing a single and a multimethod approach in group model building. Group Decis Negot 25:1277-1318. https://doi.org/10.1007/s10726-016-9480-z

Hirokawa RY (1983) Group communication and problem-solving effectiveness: an investigation of group phases. Hum Commun Res 9:291-305. https://doi.org/10.1111/j.1468-2958.1983.tb00700.x

Hovmand PS, Andersen DF, Rouwette EAJA, Richardson GP, Rux K, Calhoun A (2012) Group modelbuilding 'scripts' as a collaborative planning tool. Syst Res Behav Sci 29:179-193. https://doi.org/10. 1002/sres. 2105

Huxham C, Cropper S (1994) From many to one-and back. An exploration of some components of facilitation. Omega 22:1-11. https://doi.org/10.1016/0305-0483(94)90003-5

Keyton J, Stallworth V (2003) On the verge of collaboration: interaction processes versus group outcomes. In: Frey LR (ed) Group communication in context: studies of bona fide groups. Lawrence Erlbaum Associates, Mahwah, pp 235-260

Kim WC, Mauborgne R (1998) Procedural justice, strategic decision making, and the knowledge economy. Strateg Manag J 19:323-338. https://doi.org/10.1002/(SICI)1097-0266(199804)19:4\%3c323: AID-SMJ976\%3e3.0.CO;2-F 
Kolfschoten GL, Niederman F, Briggs RO, De Vreede GJ (2012) Facilitation roles and responsibilities for sustained collaboration support in organizations. J Manage Inf Syst 28:129-161. https://doi.org/10. 2753/mis0742-1222280406

Korsgaard MA, Schweiger DM, Sapienza HJ (1995) Building commitment, attachment, and trust in strategic decision-making teams: the role of procedural justice. Acad Manag J 38:60-84. https://doi.org/10. $2307 / 256728$

Krone KJ (1993) A review and assessment of communication research on questioning. In: Dervin B, Hariharan U (eds) Progress in communication sciences, vol 11. Ablex Publishing Corporation, Norwood, pp 179-206

Larson JR (2010) In search of synergy in small group performance. Psychology Press, New York

Larson JR, Christensen C, Franz TM, Abbott AS (1998) Diagnosing groups: the pooling, management, and impact of shared and unshared case information in team-based medical decision making. J Pers Soc Psychol 75:93-108. https://doi.org/10.1037//0022-3514.75.1.93

Maier NR (1967) Assets and liabilities in group problem solving: the need for an integrative function. Psychol Rev 74:239-249. https://doi.org/10.1037/h0024737

McCardle-Keurentjes MHF (2015) Facilitated modelling and hidden profiles: an experimental evaluation of group model building. Radboud University, Nijmegen

McFadzean E (2002) Developing and supporting creative problem solving teams: part 2-facilitator competencies. Manag Decis 40:537-551. https://doi.org/10.1108/00251740210433936

Meyer B, Burtscher MJ, Jonas K, Feese S, Arnrich B, Troster G, Schermuly CC (2016) What good leaders actually do: micro-level leadership behaviour, leader evaluations, and team decision quality. Eur J Work Organ Psychol 25:773-789. https://doi.org/10.1080/1359432x.2016.1189903

Midgley G, Cavana RY, Brocklesby J, Foote JL, Wood DRR, Ahuriri-Driscoll A (2013) Towards a new framework for evaluating systemic problem structuring methods. Eur J Oper Res 229:143-154. https: //doi.org/10.1016/j.ejor.2013.01.047

Morton A, Ackermann F, Belton V (2003) Technology-driven and model-driven approaches to group decision support: focus, research philosophy, and key concepts. Eur J Inf Syst 12:110-126. https://doi.org/ 10.1057/palgrave.ejis.3000455

Nelson T, McFadzean E (1998) Facilitating problem-solving groups: facilitator competences. Leadersh Organ Dev J 19:72-82. https://doi.org/10.1108/01437739810208647

Neuendorf KA (2002) The content analysis guidebook. Sage Publications, Thousand Oaks

Neuendorf KA (2011) Content analysis—a methodological primer for gender research. Sex Roles 64:276-289. https://doi.org/10.1007/s11199-010-9893-0

Okhuysen GA, Eisenhardt KM (2002) Integrating knowledge in groups: how formal interventions enable flexibility. Organ Sci 13:370-386. https://doi.org/10.1287/orsc.13.4.370.2947

Pettigrew AM (1992) The character and significance of strategy process research. Strateg Manag J 13:5-16. https://doi.org/10.1002/smj.4250130903

Phillips LD (2007) Decision conferencing. In: Edwards W, Miles RF Jr, Von Winterfeldt D (eds) Advances in decision analysis: from foundations to applications. Cambridge University Press, New York, pp $375-418$

Phillips LD, Phillips MC (1993) Faciliated work groups: theory and practice. J Oper Res Soc 44:533-549. https://doi.org/10.2307/2584511

Richardson GP, Andersen DF (1995) Teamwork in group model building. Syst Dyn Rev 11:113-137. https: //doi.org/10.1002/sdr.4260110203

Rosenhead J, Mingers J (eds) (2001) Rational analysis for a problematic world revisited: Problem structuring methods for complexity, uncertainty and conflict, 2nd edn. Wiley, Chichester

Rouwette EAJA (2003) Group model building as mutual persuasion. Wolf Legal Publishers, Nijmegen

Rouwette EAJA, Smeets S (2016) Conflict, consensus and the management of a good debate: exploring the deliberative assumptions of group facilitating techniques. In: Bleijenbergh I, Korzilius H, Rouwette EAJA (eds) Methods, model building and management: a liber amicorum for Jac Vennix. Institute for Management Research, Nijmegen, pp 129-146

Rouwette EAJA, Vennix JAM, van Mullekom T (2002) Group model building effectiveness: a review of assessment studies. Syst Dyn Rev 18:5-45. https://doi.org/10.1002/sdr.229

Rouwette EAJA, Vennix JAM, Felling AJA (2009) On evaluating the performance of problem structuring methods: an attempt at formulating a conceptual model. Group Decis Negot 18:567-587. https://doi. org/10.1007/s10726-007-9100-z 
Rouwette E, Bastings I, Blokker H (2011) A comparison of group model building and strategic options development and analysis. Group Decis Negot 20:781-803. https://doi.org/10.1007/s10726010-9207-5

Rouwette EAJA, Bleijenbergh I, Vennix J (2016) Group model-building to support public policy: addressing a conflicted situation in a problem neighbourhood. Syst Res Behav Sci 33:64-78. https://doi.org/10. 1002/sres.2301

Schein EH (1997) The concept of "client" from a process consultation perspective: a guide for change agents. J Organ Change Manage 10:202-216. https://doi.org/10.1108/09534819710171077

Schilling MS, Oeser N, Schaub C (2007) How effective are decision analyses? Assessing decision process and group alignment effects. Decis Anal 4:227-242. https://doi.org/10.1287/deca.1070.0101

Schultz B, Kushlis P (2006) Empirically derived training techniques for facilitators of group discussions. In: Frey LR (ed) Facilitating group communication in context: innovations and applications with natural groups, vol one: Facilitating group creation, conflict, and conversation. Hampton Press, Cresskill, p 323345

Scott RJ, Cavana RY, Cameron D (2016) Recent evidence on the effectiveness of group model building. Eur J Oper Res 249:908-918. https://doi.org/10.1016/j.ejor.2015.06.078

Simon HA (1976) From substantive to procedural rationality. In: Latsis SJ (ed) Method and appraisal in economics. Cambridge University Press, Cambridge, pp 65-86

Simon HA (1990) Invariants of human behavior. Annu Rev Psychol 41:1-19. https://doi.org/10.1146/ annurev.ps.41.020190.000245

Spano S (2006) Theory and practice in public dialogue: a case study in facilitating community transformation. In: Frey LR (ed) Facilitating group communication in context: innovations and applications with natural groups, vol One. Facilitating group creation, conflict, and conversation. Hampton Press, Cresskill, pp 271-298

Sterman JD (2000) Business dynamics: systems thinking and modeling for a complex world. The McGrawHill Companies, Boston

Stivers T (2010) An overview of the question-response system in American English conversation. J Pragmat 42:2772-2781. https://doi.org/10.1016/j.pragma.2010.04.011

Stivers T, Enfield NJ (2010) A coding scheme for question-response sequences in conversation. J Pragmat 42:2620-2626. https://doi.org/10.1016/j.pragma.2010.04.002

Tavella E, Franco LA (2015) Dynamics of group knowledge production in facilitated modelling workshops: an exploratory study. Group Decis Negot 24:451-475. https://doi.org/10.1007/s10726-014-9398-2

Tracy K, Robles J (2009) Questions, questioning, and institutional practices: an introduction. Discourse Stud 11:131-152. https://doi.org/10.1177/1461445608100941

Van de Ven AH, Delbecq AL (1974) Effectiveness of nominal, delphi, and interacting group decision making processes. Acad Manag J 17:605-621. https://doi.org/10.2307/255641

Vennix JAM (1996) Group model building: facilitating team learning using system dynamics. Wiley, Chichester

Weingart LR (1997) How did they do that? The ways and means of studying group process. Res Organ Behav 19:189-239

Wilkinson M (2004) The secrets of facilitation: the s.m.a.r.t. guide to getting results with groups. JosseyBass, San Francisco 